\title{
Resistência à compressão do solo-cimento com substituição parcial do cimento Portland por resíduo cerâmico moído
}

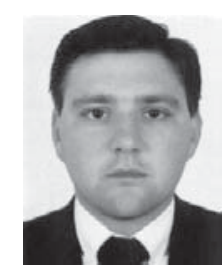

\author{
Rivanildo Dallacort ${ }^{1}$, Humberto C. Lima Júnior², Fábio L. Willrich ${ }^{3}$ \& Normando P. Barbosa ${ }^{4}$
}

${ }^{1}$ Lab. de Modelos Reduzidos/CCET/UNIOESTE. Rua Universitária 2069, CEP 85814-110, Cascavel, PR. Fone: (45) $220-3221$. E-mail: rivanildo@unioeste.br (Foto)

${ }^{2}$ Lab. de Modelos Reduzidos. E-mail: correialima@unioeste.br

${ }^{3}$ Lab. de Modelos Reduzidos. E-mail: flwillrich@unioeste.br

4 UFPB/CT. CEP 58059-900, João Pessoa, PB. Fone: (83) 246-2669. E-mail: npperazzo@lsr.ct.ufpb.br

Protocolo 59 - 29/4/2002

\begin{abstract}
Resumo: Neste trabalho, apresenta-se o estudo experimental da resistência à compressão do solo-cimento, com substituição parcial do cimento Portland por resíduo cerâmico moído. Para tanto, foram ensaiados 81 espécimenes cilíndricos desse material à compressão, em que parte do cimento foi substituída por material cerâmico moído. Realizou-se uma programação fatorial, na qual três variáveis foram selecionadas para estudo: o teor de material ligante (cimento + resíduo cerâmico), a umidade do solo e o teor de resíduo cerâmico adicionado. É apresentado um estudo estatístico através de análise de variância da massa específica do material e da resistência a compressão. Tal estudo permitiu concluir-se que substituições de 25 e $57 \%$ do teor de cimento por material cerâmico podem produzir blocos de solo-cimento com resistências superiores a $2 \mathrm{MPa}$, com teor de material ligante de 6 e $8 \%$, respectivamente.
\end{abstract}

Palavras-chave: estabilização do solo, resíduo cerâmico, resistência a compressão

\section{Compressive strength of soil-cement with partial replacement of the Portland cement by crushed ceramic waste}

\begin{abstract}
In this paper, an experimental study of the compressive strength of soil-cement with partial replacement of the Portland cement by crushed ceramic waste is presented and discussed. For this, eighty-one cylindrical specimens of soil-cement were tested, where part of cement percentage was replaced by crushed ceramic waste. The experiment was conducted in factorial design and three variables were selected and studied: the binding material content (cement + ceramic waste), soil moisture content and the ratio of ceramic waste. A statistical study using variance analysis of the specific mass and compressive strength of the material is presented. This study concluded that replacement ratios of 25 and $57 \%$ of the Portland cement by crushed ceramic material can be used to fabricate soil-cement bricks with strength higher than $2 \mathrm{MPa}$, for a binding material content of 6 and $8 \%$ respectively.
\end{abstract}

Key words: soil stabilization, ceramic waste and compressive strength

\section{INTRODUÇÃO}

Solo-cimento é definido como a mistura de solo pulverizado, cimento Portland e água que, sob compactação a um teor de umidade ótima, forma um material estruturalmente resistente, estável, durável e de baixo custo (Freire, 1976). O início da utilização deste material no Brasil data de 1936 e, atualmente, uma vasta literatura sobre o assunto pode ser encontrada (Barbosa et al., 1997). Nos últimos anos diversas pesquisas têm sido realizadas visando à redução do custo, tanto do concreto quanto da estabilização do solo, através da substituição parcial do cimento Portland por diversas adições minerais, tais como: cinza de casca de arroz, sílica ativa, metacalinita e cinza volante, entre outros (Rolim \& Freire, 1998; Akasaki \& Silva, 2001 e Farias Filho et al., 2001). Essas adições minerais possuem alguma sílica e alumínio em forma amorfa que, na presença da água, podem combinar-se quimicamente com a cal oriunda da hidratação do cimento, para formar compostos semelhantes aos silicatos e aluminatos de cálcio hidratado, o que se denomina de reação pozolânica. Este fato tem sido explorado por alguns pesquisadores visando, além de melhorar as propriedades mecânicas do solo estabilizado, diminuir a alcalinidade desse material, quando da utilização de fibras naturais. Outras adições usadas no cimento, como o pó 
de calcário moído, não possuem ação pozolânica porém, devido à elevada finura, seus grãos podem preencher os vazios entre as partículas maiores do cimento aumentando, assim, a compacidade do solo e, por conseqüência, sua resistência. A este efeito dá-se o nome de efeito fíler. Outro fator de incentivo da utilização das adições minerais é que a maioria delas é subproduto ou resíduo industrial.

Um material que se enquadra dentro dos especificados acima e que pode ser utilizado como estabilizante do solo, é o resíduo cerâmico, proveniente da construção civil e de olarias (Ay \& Ünal, 2000). Atualmente, o Brasil gera cerca de $90 \mathrm{~kg}$ por habitante por ano desse resíduo, que é quase todo lançado ao meio ambiente, sem nenhum tratamento (Pinto, 1999). A maioria das argilas, com as quais se fabricam blocos cerâmicos, em estado natural possui pequena atividade pozolânica porém, quando calcinada a uma temperatura da ordem de 700 a $900^{\circ} \mathrm{C}$, torna-se reativa. $\mathrm{O}$ tratamento térmico destrói a estrutura cristalina da argila e a transforma em uma estrutura sílicoaluminosa amorfa. Este material, quando moído, apresenta composição físico-química dentro das especificadas pela ASTM 618 (ASTM, 1992) para uso como adição mineral em misturas com cimento Portland.

O presente trabalho tem como objetivo principal investigar o comportamento à compressão do solo estabilizado com cimento Portland, no qual parte do cimento foi substituída por resíduos cerâmicos finamente pulverizados. Assim, foi analisado o efeito da substituição na capacidade portante do solo estabilizado com diversas combinações das variáveis: umidade, teor de material ligante e taxa de substituição do cimento por resíduo cerâmico. São apresentadas análises estatísticas e equações da variação da massa específica aparente e do comportamento à compressão desse material em relação às variáveis estudadas.

\section{MATERIAL E MÉTODOS}

\section{Solo}

Utilizou-se o solo Latossolo Bruno Disftrófico, oriundo de lixiviação intensa, com pH ácido e altos teores de óxido de ferro e alumínio, obtido na Universidade Estadual do Oeste do Paraná, Campus de Cascavel, tendo sido retirada a camada superficial de cerca $60 \mathrm{~cm}$, rejeitada devido à presença de matéria orgânica. Foram extraídos cerca de $1200 \mathrm{~kg}$ do material, que foi levado ao laboratório e deixado para secar sobre lona plástica, à sombra, pelo período de um mês. Neste tempo, o solo foi revirado a cada dois dias. Após a secagem, foi ensacado e, em seguida, foram retiradas seis amostras para análise granulométrica, realizada segundo a NBR 7181 (ABNT, 1984d) e mais seis para determinação dos limites de plasticidade e de liquidez e do índice de plasticidade, obtidos segundo a NBR 7180 (ABNT, 1984b) e NBR 6459 (ABNT, 1984a). A análise granulométrica mostrou que se tratava de um solo argiloso, com $80,02 \%$ de argila, $17,5 \%$ de silte e $2,3 \%$ de areia fina, bem como com limites de liquidez e de plasticidade e índice de plasticidade de 53, 32 e $21 \%$, respectivamente.

Segundo Freire (1976) solos com altas concentrações de argila necessitam de teores de cimento elevados, devido à grande área superficial dos grãos. A ABCP (1989) sugere que, para um consumo mínimo de cimento, o solo deve apresentar teores de argila mais silte e areia, da ordem de 35 e $65 \%$, e limite de liquidez, limite de plasticidade e índice de plasticidade inferiores a 45,18 e $10 \%$, respectivamente.

Com base no exposto, decidiu-se realizar uma correção granulométrica do solo, de forma a satisfazer os limites sugeridos pela ABCP (1989). Esta correção consistiu em se adicionar, para cada $35 \mathrm{~kg}$ de solo seco em estufa, $65 \mathrm{~kg}$ de areia quartzosa extraída do Rio Paraná, com módulo de finura de 2,11, diâmetro máximo característico de $2,4 \mathrm{~mm}$ e massa específica aparente de $2,65 \mathrm{~kg} \mathrm{dm}^{-3}$. A mistura foi realizada em uma betoneira de $250 \mathrm{~L}$, por um período de $10 \mathrm{~min}$. Após a mistura, foram retiradas novamente seis amostras para análise granulométrica e mais seis para determinação dos limites de plasticidade e liquidez e do índice de plasticidade. A Figura 1 apresenta a curva granulométrica do solo obtido após a mistura, que resultou em um solo areno-argiloso, dentro dos padrões sugeridos pela $\mathrm{ABCP}$ (1989) com $0,2 \%$ de pedregulho, $19,9 \%$ de areia grossa, $43,8 \%$ de areia fina, $8,1 \%$ de silte e $28,0 \%$ de argila. Os limites de liquidez e plasticidade deste solo, bem como o seu índice de plasticidade, eram de 19,01, 11,96 e 7,05\%, respectivamente.

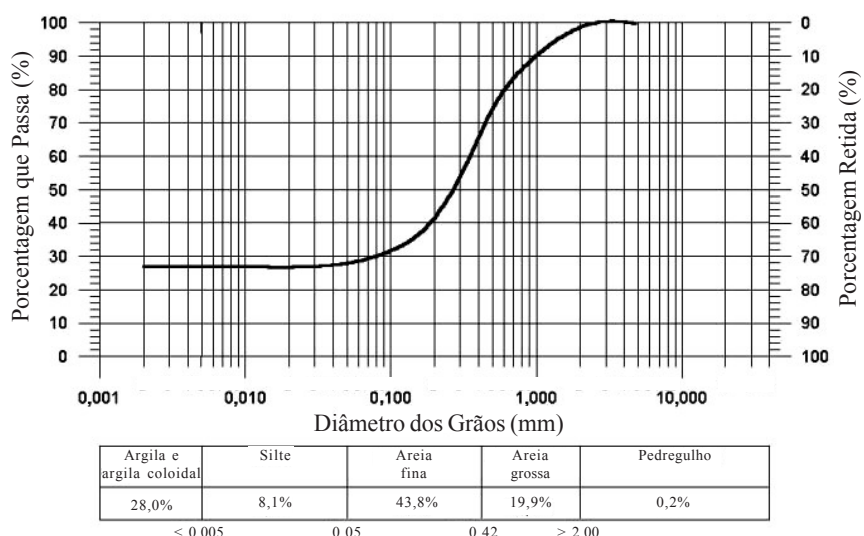

Figura 1. Curva granulométrica do solo corrigido com areia quartzosa

\section{Cimento}

Utilizou-se cimento Portland de alta resistência inicial - CP V ARI, cuja caracterização físico-química foi realizada pelo fabricante e tem os resultados apresentados na Tabela 1.

\section{Resíduo cerâmico}

Os resíduos cerâmicos foram obtidos em olaria local da cidade de Cascavel, PR, e eram constituídos por blocos cerâmicos com pequenas trincas, provocadas pelo processo de queima e que, por isso, foram rejeitados no controle de qualidade da empresa. Os blocos utilizados foram calcinados a uma temperatura de 800 a $900{ }^{\circ} \mathrm{C}$ por um período de $10 \mathrm{~h}$. Os mesmos foram selecionados, levados ao laboratório e moídos na máquina para ensaio de Abrasão Los Angeles (NBR-6465 ABNT, 1984b). Após a moagem, os resíduos foram peneirados, de maneira que foi utilizado apenas o material passante na peneira ABNT $300(0,05 \mathrm{~mm})$. O material retido na peneira era devolvido à máquina Los Angeles, para mais um ciclo de moagem. Após a moagem de todo o material, este foi armazenado em sacos plásticos e amostras foram retiradas para 
Tabela 1. Propriedades físico-químicas do cimento

\begin{tabular}{|c|c|}
\hline \multicolumn{2}{|l|}{ Ensaios Físicos } \\
\hline Resíduo na peneira ABNT n ${ }^{\circ} 200(\%)$ & 0,08 \\
\hline Resíduo na peneira ABNT n $325(\%)$ & 1,76 \\
\hline Área específica Blaine $\left(\mathrm{m}^{2} \mathrm{~kg}^{-1}\right)$ & 4339,00 \\
\hline Início de pega (min) & 184,00 \\
\hline Fim de pega (min) & 261,00 \\
\hline Expansibilidade a quente (mm) & 0,00 \\
\hline Resistência a compressão (MPa) - $1 \mathrm{~d}$ & 26,50 \\
\hline Resistência a compressão (MPa) - $3 \mathrm{~d}$ & 40,50 \\
\hline Resistência a compressão (MPa) - $7 \mathrm{~d}$ & 43,10 \\
\hline Resistência a compressão (MPa) - 28 d & 54,10 \\
\hline Massa específica $\left(\mathrm{g} \mathrm{dm}^{-3}\right)$ & 3,130 \\
\hline \multicolumn{2}{|l|}{ Ensaios Químicos } \\
\hline Perda ao fogo $(\%)$ & 2,88 \\
\hline $\mathrm{C}_{2} \mathrm{~S}(\%)$ & 5,44 \\
\hline $\mathrm{C}_{3} \mathrm{~S}(\%)$ & 64,58 \\
\hline $\mathrm{C}_{3} \mathrm{~A}(\%)$ & 6,78 \\
\hline $\mathrm{CaO}$ livre (\%) & 0,73 \\
\hline $\mathrm{MgO}$ livre $(\%)$ & 1,99 \\
\hline $\mathrm{K}_{2} \mathrm{O}(\%)$ & 0,81 \\
\hline $\mathrm{Na}_{2} \mathrm{O}(\%)$ & 0,03 \\
\hline $\mathrm{SO}_{3}(\%)$ & 3,00 \\
\hline Resíduo insolúvel (\%) & 0,34 \\
\hline Água de consistência (\%) & 28,15 \\
\hline
\end{tabular}

análise físico-química. Os ensaios físicos consistiram-se na determinação da massa, da área específica e do índice de atividade pozolânica do material; já os químicos, na análise de espectrometria de raio $\mathrm{X}$.

\section{Ensaio de compactação}

Para a obtenção da umidade ótima do solo, foi utilizado o ensaio de Proctor Modificado. O teste consistiu em compactar amostras de solos com diferentes umidades em um molde cilíndrico metálico, com 96,2 mm de diâmetro e 127,3 mm de altura, em três camadas, por meio de 25 golpes de um soquete de $5 \mathrm{~kg}$, caindo de uma altura de $45 \mathrm{~cm}$. Após a compactação, o cilindro de solo era retirado do molde e pesado em uma balança eletrônica com precisão de $0,1 \mathrm{~g}$; em seguida, três amostras do solo foram extraídas do cilindro, pesadas em balança eletrônica com precisão de $0,001 \mathrm{~g}$ e levadas à estufa a uma temperatura de $100^{\circ} \mathrm{C}$, por $24 \mathrm{~h}$. Ao término deste período, as amostras eram novamente pesadas e suas umidades calculadas. Com os valores das massas dos cilindros de solo e as respectivas umidades, foi possível obter-se a curva de compactação do material, que está representada na Figura 2. Analisando-se esta, verifica-se que a umidade ótima e a respectiva massa específica aparente são iguais a $15,34 \% \mathrm{e} 1938,10 \mathrm{~kg} \mathrm{~m}^{-3}$, respectivamente. Devido à variação de umidade do solo seco ao ar, foram selecionados três níveis de umidade para análise, de modo que a umidade ótima se localizasse entre os valores escolhidos. Foram escolhidas, então, as umidades de 12, 14 e 16\%, cujas massas específicas aparentes são 1830,62, 1919,63 e 1933,29 $\mathrm{kg} \mathrm{m}^{-3}$, respectivamente.

\section{Variáveis estudadas e preparação dos corpos-de-prova}

O procedimento de escolha das variáveis e os níveis de investigação foram obtidos através de uma programação fatorial de experimentos (Montgomery, 1984). Três variáveis foram escolhidas como fatores principais de avaliação: a percentagem

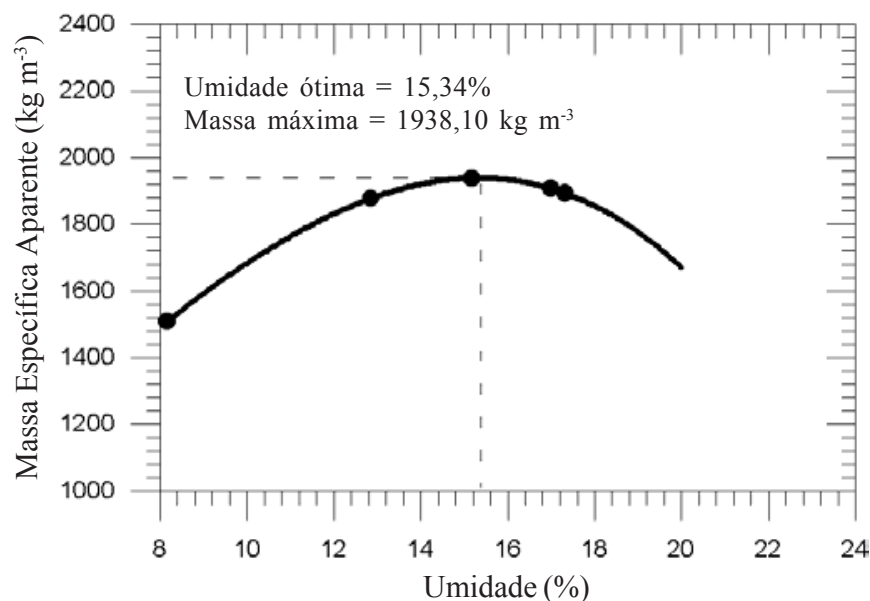

Figura 2. Curva de compactação do solo

de material ligante (cimento + material cerâmico) adicionada $\left(\mathrm{X}_{1}\right)$, o teor de umidade da mistura $\left(\mathrm{X}_{2}\right)$ e o teor de material cerâmico em substituição ao cimento $\left(\mathrm{X}_{3}\right)$. Foram escolhidos três níveis de estudo para cada variável, resultando em um projeto fatorial $3^{3}$. Os três níveis de estudo do material ligante adicionado, foram 6,8 e 10\%; do teor de umidade foram 12,14 e $16 \%$; e do teor de material cerâmico, foram 0,25 e $50 \%$. Para cada combinação de variáveis foram ensaiados três espécimenes.

Os espécimenes foram moldados em formas metálicas cilíndricas, com altura de $20 \mathrm{~cm}$ e diâmetro de $10 \mathrm{~cm}$. O solo apresentava umidade natural da ordem de 4,5\%; entretanto, para a verificação exata da umidade, três amostras de solo de cada masseira foram extraídas, segundos antes da mistura, e levadas à estufa para secagem a $100^{\circ} \mathrm{C}$, por um período de $24 \mathrm{~h}$, para futuras correções. Então, os materiais (solo, cimento, resíduo cerâmico e água) foram misturados em uma betoneira de $150 \mathrm{~L}$ por um período de $15 \mathrm{~min}$; em seguida, a mistura foi lançada dentro dos moldes em três camadas, e cada camada compactada com 25 golpes do soquete do ensaio de Proctor. Foi utilizado um funil metálico, com diâmetro de $10 \mathrm{~cm}$, para auxiliar a compactação da última camada. Ao término da compactação, um centímetro da parte superior dos espécimenes foi extraído com uma espátula e preenchido com argamassa de cimento Portland, no traço 1:2, fator água-cimento 0,3 e resistência à compressão média igual a 40,25 $\mathrm{MPa}$. Este procedimento visou garantir a uniformidade na compactação do solo-cimento, ao longo de toda a altura dos espécimenes e permitir, também, um acabamento melhor da superfície superior desses. Após a moldagem, os espécimenes foram deixados nas formas e cobertos com uma lona plástica, durante sete dias. Após o término do período de cura, os espécimenes foram desmoldados, pesados e tiveram suas extremidades inferior e superior capeadas com enxofre. Na Figura 3A apresenta-se o aspecto dos espécimenes analisados.

\section{Ensaio e instrumentação}

Os espécimenes foram ensaiados em um pórtico metálico rígido (Fig. 3B), com capacidade de carga de $100 \mathrm{kN}$. Ao pórtico foi associado um atuador hidráulico, com capacidade de carga de $100 \mathrm{kN}$ e controle de carregamento manual. Uma célula de carga de $50 \mathrm{kN}$ foi acoplada ao sistema e as leituras foram obtidas por um sistema de aquisição de dados. Placas rígidas 
A.

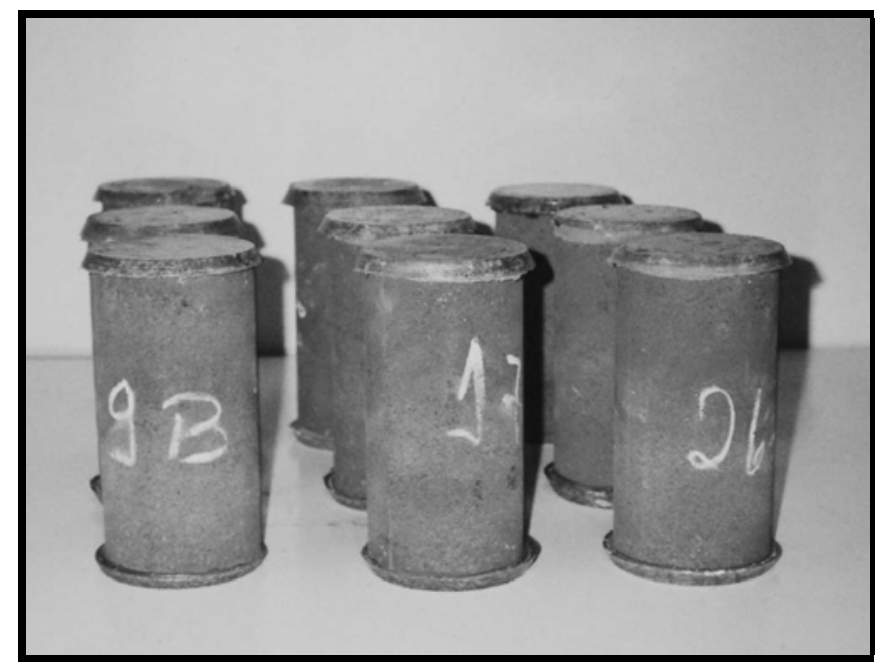

B.

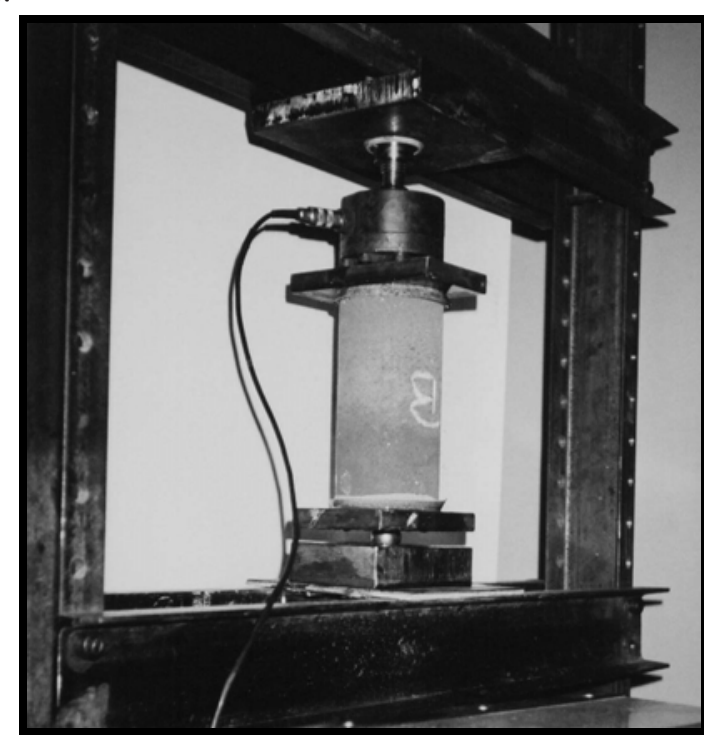

Figura 3. Aspecto dos espécimes analisados (A) e pórtico do ensaio de compressão simples (B)

de aço foram dispostas nas extremidades dos espécimenes e uma rótula bidirecional na extremidade inferior. Antes do posicionamento de cada espécime no sistema de ensaio, as placas superior e inferior eram limpas e lubrificadas com óleo, e películas de teflon de $0,4 \mathrm{~mm}$ eram posicionadas entre as placas e os espécimenes. O carregamento foi aplicado continuamente até o colapso dos corpos-de-prova, a uma taxa da ordem de $0,5 \mathrm{kN} \mathrm{s}^{-1}$. A leitura da carga máxima era obtida através do bloqueador de pico do sistema de aquisição de dados.

\section{RESULTADOS E DISCUSSÃO}

\section{Análise físico-química do resíduo cerâmico moído}

A composição química, finura e densidade do material cerâmico moído, são apresentadas na Tabela 2. A composição química do material indica que o mesmo apresenta teor de $\mathrm{SiO}_{2}+$ $\mathrm{Al}_{2} \mathrm{O}_{3}+\mathrm{Fe}_{2} \mathrm{O}_{3}$ superior a $70 \%, \mathrm{MgO}$ inferior a $3 \%, \mathrm{SO}_{3}$ inferior a $3 \%$ e CaO inferior a $10 \%$, limites esses estabelecidos pela ASTM 618 C (ABNT, 1992) para o uso como adição mineral em misturas com cimento Portland. O índice de atividade pozolânica calculada segundo a NBR - 5752 (ABNT, 1992) foi de 84,21\%. Esses resultados mostram que o resíduo cerâmico moído pode ser utilizado com material pozolânico.

Tabela 2. Propriedades físico-químicas do resíduo cerâmico

Ensaios Físicos
Resíduo na peneira $\mathrm{ABNT} \mathrm{n}^{\circ} 300(\%)$

Área específica Blaine $\left(\mathrm{m}^{2} \mathrm{~kg}^{-1}\right)$

Massa específica $\left(\mathrm{kg} \mathrm{dm}^{-3}\right)$

\begin{tabular}{lr}
\hline & Ensaios Químicos \\
Perda ao fogo (\%) & 2,12 \\
$\mathrm{SiO}_{2}(\%)$ & 58,00 \\
$\mathrm{Al}_{2} \mathrm{O}_{3}(\%)$ & 26,00 \\
$\mathrm{Fe}_{2} \mathrm{O}_{3}(\%)$ & 7,80 \\
$\mathrm{CaO}(\%)$ & 0,60 \\
$\mathrm{MgO}(\%)$ & 0,30 \\
$\mathrm{~K}_{2} \mathrm{O}(\%)$ & 0,29 \\
$\mathrm{Na}_{2} \mathrm{O}(\%)$ & 0,07 \\
$\mathrm{SO}_{3}(\%)$ & 0,40 \\
$\mathrm{TiO}_{2}(\%)$ & 4,42 \\
\hline
\end{tabular}

\section{Comportamento global do ensaio}

Os procedimentos de ensaio e moldagem dos espécimenes mostraram-se adequados, e se observou uma aparente uniformidade entre as réplicas, quanto aos valores das resistências e das massas específicas. Dois modos de ruptura também foram observados: colapso por cisalhamento paralelo ao plano, a $45^{\circ}$ com o eixo vertical, ocorrendo formação de cone nas extremidades dos espécimenes, e colapso por tração perpendicular ao eixo de aplicação da carga. Não foi observada, em nenhum espécime, a formação de linha de ruptura entre as camadas de compactação do solo nem entre o solo e a camada de argamassa. A camada de argamassa e a região de interação soloargamassa permaneceram íntegras até a ruptura dos espécimes (Fig. 4).

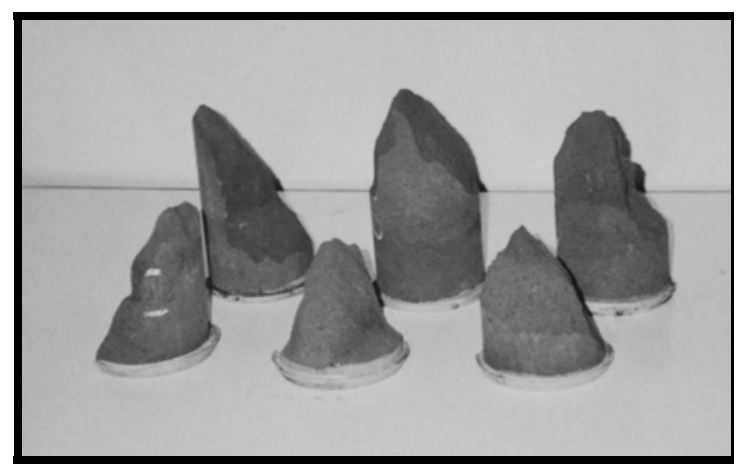

Figura 4. Aspecto dos espécimes após ensaio

A análise da umidade natural do solo, no instante da mistura com o cimento, apresentou valor médio de $4,30 \%$ e desvio padrão de $0,64 \%$, valor pouco inferior ao adotado $(4,5 \%)$. Apesar da pequena diferença, optou-se por corrigir os níveis de umidade estudados de 12, 14 e 16 para 11,8, 13,8 e 15,8\%, durante a análise dos resultados.

\section{Análise da massa específica aparente}

$\mathrm{Na}$ Tabela 3 tem-se as massas específicas dos espécimes de solo-cimento. As massas específicas médias para as 
Tabela 3. Massa específica aparente dos espécimes $\left(\mathrm{kg} \mathrm{m}^{-3}\right)$

\begin{tabular}{|c|c|c|c|c|c|c|c|c|c|}
\hline \multirow{4}{*}{$\begin{array}{c}\mathrm{X}_{1} \\
\text { (Teor de } \\
\text { Ligante) } \\
-\%\end{array}$} & \multicolumn{9}{|c|}{$\mathrm{X}_{2}$ (Umidade) - \% } \\
\hline & \multicolumn{3}{|c|}{11,8} & \multicolumn{3}{|c|}{13,8} & \multicolumn{3}{|c|}{15,8} \\
\hline & \multicolumn{9}{|c|}{$\mathrm{X}_{3}$ (Teor de Substituição) - \% } \\
\hline & 0 & 25 & 50 & 0 & 25 & 50 & 0 & 25 & 50 \\
\hline \multirow{3}{*}{6} & 1807,13 & 1807,07 & 1844,59 & 1876,50 & 1965,22 & 1995,03 & 2041,15 & 1977,64 & 1986,88 \\
\hline & 1800,57 & 1829,62 & 1866,24 & 1883,50 & 1987,77 & 1992,68 & 2019,62 & 1984,20 & 1977,58 \\
\hline & 1774,90 & 1822,10 & 1829,68 & 1914,20 & 1938,79 & 1966,43 & 1984,97 & 2059,49 & 1998,47 \\
\hline \multirow{3}{*}{8} & 1845,48 & 1904,14 & 1878,92 & 2010,00 & 1949,81 & 1921,91 & 2004,90 & 1998,47 & 1973,63 \\
\hline & 1880,89 & 1936,82 & 1799,11 & 2013,63 & 2006,69 & 1881,08 & 2008,28 & 1982,04 & 1957,01 \\
\hline & 1893,31 & 1906,88 & 1840,76 & 1996,69 & 1989,75 & 1899,68 & 1988,09 & 1977,58 & 1996,31 \\
\hline \multirow{3}{*}{10} & 1748,54 & 1824,33 & 1743,82 & 1847,32 & 1903,89 & 1876,75 & 1967,26 & 1930,32 & 1965,73 \\
\hline & 1774,90 & 1841,34 & 1707,24 & 1840,70 & 1922,74 & 1852,55 & 1969,17 & 1939,81 & 1944,71 \\
\hline & 1767,39 & 1872,04 & 1711,97 & 1841,08 & 1942,29 & 1898,85 & 1973,69 & 1935,54 & 1937,83 \\
\hline
\end{tabular}

umidades de $11,8,13,8$ e $15,8 \%$ foram $1824,44,1930,20$ e 1980,75 $\mathrm{kg} \mathrm{m}^{-3}$, respectivamente, valores que diferem menos que $3 \%$ dos obtidos no ensaio de Proctor e que comprovam compactação semelhante entre os dois procedimentos. Segundo PCA (1976) a massa específica é considerada alta quando se situa entre 2000 e $2320 \mathrm{~kg} \mathrm{~m}^{-3}$, e baixa quando se situa entre $1360 \mathrm{e}$ $1600 \mathrm{~kg} \mathrm{~m}^{-3}$. Esta Associação afirma ainda que, quanto maior a massa específica, maior será a resistência do material para o mesmo solo e o mesmo teor de cimento, e que um decréscimo de $20 \mathrm{~kg} \mathrm{~m}^{-3}$ na massa específica aparente implica em um decréscimo de 0,11 MPa na resistência do solo-cimento. A maioria das prensas manuais utilizadas para fabricação de blocos de solo-cimento, aplica pressão estática na compactação do material, da ordem de $2 \mathrm{MPa}$, que leva a valores de massa específica média da ordem de $1800 \mathrm{~kg} \mathrm{~m}^{-3}$. Observa-se que os valores das massas específicas obtidos nos espécimes aqui testados, se situaram entre 1800 e $2000 \mathrm{~kg} \mathrm{~m}^{-3}$.

Para se analisar a influência de cada variável sobre a massa específica aparente do solo-cimento, realizou-se uma análise de variância. Os graus de significância do efeito de cada variável foram testados para um nível de confiabilidade de 95 e $99 \%$, usando-se o teste F. Na Tabela 4 são apresentados os resultados da análise. Com base nesses resultados, observa-se que o fator de influência mais importante é a umidade do solo, seguida pelo teor de material ligante e pelo teor de material cerâmico moído. As três variáveis principais são significantes em um nível de confiabilidade de $99 \%$. Observa-se, ainda, que todos os acoplamentos também apresentam significância em um nível de confiabilidade de $99 \%$.
A influência da umidade do solo na massa específica do solo-cimento, até o valor ótimo, está ligada à lubrificação das partículas do solo, que lhes permite melhor rearranjo, de forma a ocupar o menor volume possível. Ultrapassado o valor ótimo, a água começa a ocupar espaço entre as partículas, provocando diminuição da densidade; já o material ligante, composto pelo cimento e pelo resíduo de blocos moídos, além de criar, com sua hidratação, um esqueleto sólido entre os grãos do solo, tem também o efeito de micro-filer, preenchendo os pequenos vazios entre as partículas de solo, interferindo na massa específica do material.

Com o objetivo de se obter uma equação que correlacione a massa específica do solo-cimento com as variáveis estudadas, realizou-se uma análise de regressão múltipla não-linear com os dados apresentados na Tabela 3. A equação obtida apresentou coeficiente de determinação, $\mathrm{R}^{2}$, de 0,95 , e é dada pela Eq. (1):

$$
\begin{aligned}
\gamma= & -658,697+182,956 X_{1}+5,249 X_{2}+235,843 X_{3}-0,248 X_{1} X_{2}- \\
& 0,525 X_{1} X_{3}-0,082 X_{2} X_{3}-11,434 X_{1}^{2}-0,046 X_{2}^{2}-6,902 X_{3}^{2}
\end{aligned}
$$

na qual $\gamma$ é a massa específica aparente $\mathrm{em} \mathrm{kg} \mathrm{cm}^{-3}$. Na Figura 5 tem-se as curvas (relativas à Eq. 1) para os diferentes teores de material ligante. Observa-se que, para um teor de material cerâmico moído da ordem de $25 \%$ e de material ligante $6 \%$, obtém-se uma massa específica máxima; entretanto, com o aumento do teor de material ligante, esta percentagem decresce. Observa-se, ainda, que para $0 \%$ de material cerâmico, a máxima massa específica é obtida com aproximadamente $8 \%$ de material

\begin{tabular}{|c|c|c|c|c|c|c|}
\hline Variáveis & Soma dos Quadrados & Graus de Liberdade & Média dos Quadrados & Fator $\left(\mathrm{F}_{\mathrm{o}}\right)$ & $\mathrm{F}_{0.05, \mathrm{n}, 80}$ & $\mathrm{~F}_{0.01, \mathrm{n}, 80}$ \\
\hline \multicolumn{7}{|l|}{ Fatores principais } \\
\hline $\mathrm{X}_{1}$ & 76603,8 & 2 & 38301,9 & 87,3396 & 3,123 & 4,916 \\
\hline$X_{2}$ & 343598,5 & 2 & 171799,2 & 391,7528 & 3,123 & 4,916 \\
\hline $\mathrm{X}_{3}$ & 15862,7 & 2 & 7931,3 & 18,0858 & 3,123 & 4,916 \\
\hline \multicolumn{7}{|l|}{ Interações } \\
\hline $\mathrm{X}_{1} \times \mathrm{X}_{2}$ & 15103,7 & 4 & 3775,9 & 8,6102 & 2,503 & 3,593 \\
\hline $\mathrm{X}_{1} \times \mathrm{X}_{3}$ & 24162,2 & 4 & 6040,5 & 13,7742 & 2,503 & 3,593 \\
\hline $\mathrm{X}_{2} \times \mathrm{X}_{3}$ & 14331,6 & 4 & 3582,9 & 8,1700 & 2,503 & 3,593 \\
\hline $\mathrm{X}_{1} \times \mathrm{X}_{2} \times \mathrm{X}_{3}$ & 29241,3 & 8 & 3655,1 & 8,3348 & 2,073 & 2,767 \\
\hline Erro & 23681,1 & 54 & 438,5 & -- & & \\
\hline Total & 542585,2 & 80 & -- & -- & & \\
\hline
\end{tabular}

Tabela 4. Análise de variância da massa específica aparente 
A.

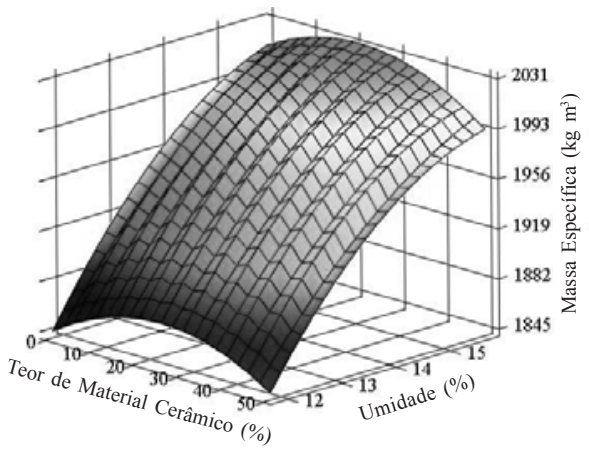

D.

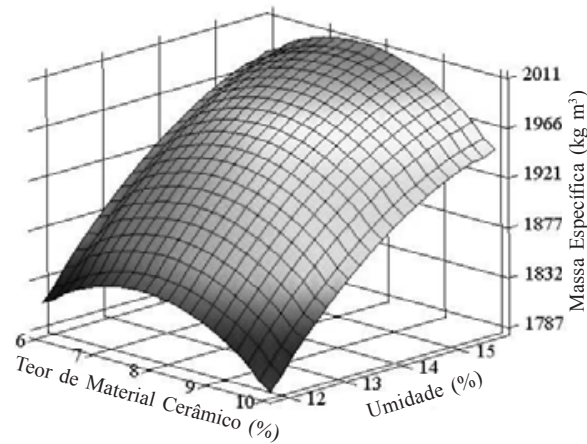

B.

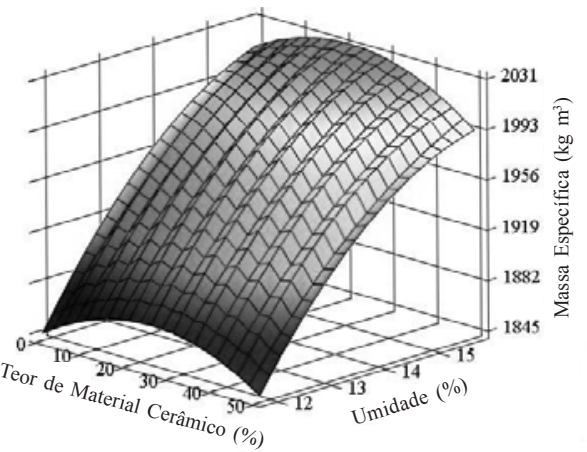

E.

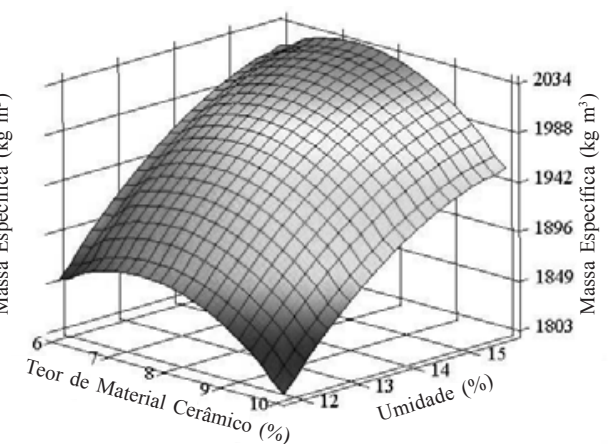

C.

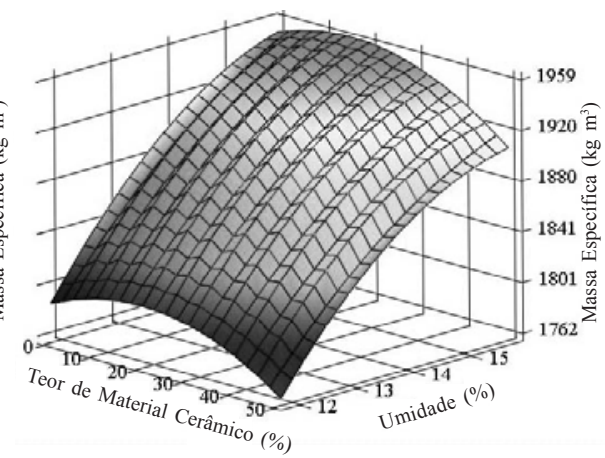

F.

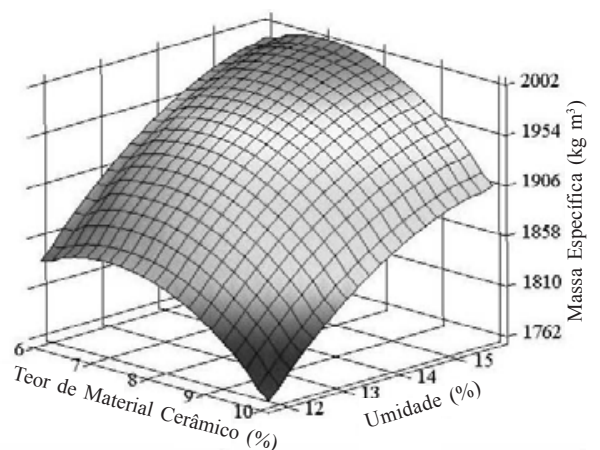

Figura 5. Representação gráfica da Eq. (1) para os teores de material ligante $6 \%(\mathrm{~A}), 8 \%(\mathrm{~B})$ e $10 \%$ (C) e para os teores de material cerâmico $0 \%$ (D), 25\% (E) e 50\% (F)

ligante; porém, com a elevação do teor de material cerâmico, o teor ótimo de material ligante diminui.

\section{Avaliação da resistência a compressão}

$\mathrm{Na}$ Tabela 5 são apresentadas as resistências à compressão dos espécimenes de solo-cimento. Observa-se que, para $11,8 \%$ de umidade, a substituição de $25 \%$ de cimento por material cerâmico eleva a resistência do material, em 25,85\% e, para substituição de $50 \%$, ocorre decréscimo na resistência, de $35,17 \%$. Para $13,8 \%$ de umidade, a substituição de $25 \%$ de cimento por material cerâmico eleva a resistência do material em $10,60 \%$ e, para substituição de $50 \%$, acontece um decréscimo na resistência, de 30,32\%. Finalmente, para 15,8\% de umidade a substituição de 25 e $50 \%$ de cimento por material cerâmico reduz a resistência do material, em 16,07 e 40,69\%, respectivamente.

Olivier et al. (1995) afirmam que a resistência mínima de $2 \mathrm{MPa}$ é suficiente para garantir a qualidade de blocos de solo- cimento, porém na fabricação de blocos de solo-cimento com prensa manual, a energia de compactação do material é inferior à utilizada neste trabalho, o que significa que, para as mesmas proporções e mesmos materiais, os blocos apresentarão resistências inferiores àquelas aqui encontradas. Deste modo, pode-se utilizar a diferença das massas específicas entre os blocos e os espécimenes estudados para estabelecer coeficientes de correlação entre as resistências. Assim, para 6\% de material ligante e umidades de $15,8 \%$, a massa específica média dos espécimes foi $2003 \mathrm{~kg} \mathrm{~m}^{-3}$, isto é, aproximadamente $200 \mathrm{~kg} \mathrm{~m}^{-3} \mathrm{a}$ mais que a massa específica média dos blocos. Considerandose, então, que para um decréscimo de $20 \mathrm{~kg} \mathrm{~m}^{-3}$ implica em uma diminuição de $0,11 \mathrm{MPa}$ na resistência do solo-cimento (PCA, 1976) tem-se que as resistências dos espécimenes serão cerca de $1,1 \mathrm{MPa}$ superiores às dos blocos. Observa-se, assim, que teores de substituição do cimento por material cerâmico da ordem de $25 \%$, são viáveis.

Tabela 5. Resistência à compressão dos espécimes (MPa)

\begin{tabular}{|c|c|c|c|c|c|c|c|c|c|}
\hline \multirow{4}{*}{$\begin{array}{c}\mathrm{X}_{1} \\
\text { (Teor de } \\
\text { ligante) - } \\
\%\end{array}$} & \multicolumn{9}{|c|}{$\mathrm{X}_{2}$ (Umidade) - \% } \\
\hline & \multicolumn{3}{|c|}{11,8} & \multicolumn{3}{|c|}{13,8} & \multicolumn{3}{|c|}{15,8} \\
\hline & \multicolumn{9}{|c|}{$\mathrm{X}_{3}$ (Teor de Substituição) - \% } \\
\hline & 0 & 25 & 50 & 0 & 25 & 50 & 0 & 25 & 50 \\
\hline \multirow{3}{*}{6} & 1,411 & 1,171 & 1,287 & 2,895 & 2,236 & 2,217 & 4,922 & 3,106 & 2,147 \\
\hline & 1,261 & 1,258 & 0,964 & 2,811 & 2,985 & 2,578 & 4,986 & 4,229 & 2,061 \\
\hline & 1,337 & 1,147 & 0,764 & 3,043 & 2,859 & 1,939 & 4,170 & 3,067 & 2,137 \\
\hline \multirow{3}{*}{8} & 2,284 & 3,248 & 2,245 & 5,736 & 4,316 & 2,573 & 5,881 & 5,513 & 3,494 \\
\hline & 2,044 & 4,194 & 1,287 & 6,057 & 5,693 & 2,354 & 5,978 & 4,790 & 3,120 \\
\hline & 3,285 & 3,332 & 1,827 & 5,708 & 5,103 & 2,510 & 5,634 & 5,287 & 3,603 \\
\hline \multirow{3}{*}{10} & 1,855 & 2,474 & 1,244 & 3,302 & 4,655 & 3,020 & 5,918 & 5,199 & 4,929 \\
\hline & 1,755 & 2,701 & 0,710 & 3,051 & 4,911 & 2,200 & 5,760 & 5,557 & 4,162 \\
\hline & 2,238 & 2,865 & 0,767 & 3,216 & 5,065 & 3,339 & 6,275 & 5,135 & 4,170 \\
\hline
\end{tabular}


Tabela 6. Análise de variância da resistência a compressão

\begin{tabular}{|c|c|c|c|c|c|c|}
\hline Variáveis & Soma dos Quadrados & Graus de Liberdade & Média dos Quadrados & Fator $\left(\mathrm{F}_{\mathrm{o}}\right)$ & $\mathrm{F}_{0.05, \mathrm{n}, 80}$ & $\mathrm{~F}_{0.01, \mathrm{n}, 80}$ \\
\hline \multicolumn{7}{|l|}{ Fatores principais } \\
\hline$X_{1}$ & 35,5214 & 2 & 17,76072 & 132,9445 & 3,123 & 4,916 \\
\hline $\mathrm{X}_{2}$ & 94,0641 & 2 & 47,03210 & 352,0498 & 3,123 & 4,916 \\
\hline $\mathrm{X}_{3}$ & 37,1933 & 2 & 18,59667 & 139,2018 & 3,123 & 4,916 \\
\hline \multicolumn{7}{|l|}{ Interações } \\
\hline$X_{1} \times X_{2}$ & 5,3878 & 4 & 1,34695 & 10,0824 & 2,503 & 3,593 \\
\hline $\mathrm{X}_{1} \times \mathrm{X}_{3}$ & 7,3019 & 4 & 1,82548 & 13,6643 & 2,503 & 3,593 \\
\hline $\mathrm{X}_{2} \times \mathrm{X}_{3}$ & 6,7888 & 4 & 1,69720 & 12,7041 & 2,503 & 3,593 \\
\hline $\mathrm{X}_{1} \times \mathrm{X}_{2} \times \mathrm{X}_{3}$ & 7,9242 & 8 & 0,99053 & 7,4144 & 2,073 & 2,767 \\
\hline Erro & 7,2141 & 54 & 0,13359 & -- & & \\
\hline Total & 201,3960 & 80 & -- & -- & & \\
\hline
\end{tabular}

Para se analisar a influência de cada variável sobre a resistência dos espécimenes de solo-cimento, também se realizou uma análise de variância. Os graus de significância do efeito de cada variável foram testados para um nível de confiabilidade de 95 e $99 \%$, usando-se o teste F. Na Tabela 6 são apresentados os resultados da análise. Observa-se novamente que o fator de influência mais importante é a umidade do solo, seguida pelos teores de material cerâmico moído e de material ligante. As três variáveis principais são significantes em um nível de confiabilidade de $99 \%$. Constata-se, ainda, que todos os acoplamentos também apresentam significância em um nível de confiabilidade de $99 \%$.

Seguindo-se o mesmo procedimento do item anterior, realizou-se uma análise de regressão múltipla não-linear com os dados apresentados na Tabela 5, objetivando-se a obtenção de uma equação que correlacionasse a resistência à compressão do material estudado com as variáveis analisadas. A equação obtida apresentou um coeficiente de determinação, $\mathrm{R}^{2}$, de 0,97 e é dada pela Eq. (2):

$$
\begin{aligned}
\sigma= & -34,816+3,187 \mathrm{X}_{1}+0,121 \mathrm{X}_{2}+2,892 \mathrm{X}_{3}+1,063 \times 10^{-3} \mathrm{X}_{1} \mathrm{X}_{2}+ \\
& +0,071 \mathrm{X}_{1} \mathrm{X}_{3}-7,403 \times 10^{-3} \mathrm{X}_{2} \mathrm{X}_{3}-0,244 \mathrm{X}_{1}^{2}-1,118 \times 10^{-3} \mathrm{X}_{2}^{2}- \\
& 0,095 \mathrm{X}_{3}^{2}
\end{aligned}
$$

na qual $\sigma$ é a resistência à compressão do solo-cimento em (MPa). Na Figura 6 tem-se as curvas (relativas à Eq. 2) para os diferentes teores de material ligante e material cerâmico. Analisando-se as curvas da Figura 6 e se considerando uma perda de resistência de $0,14,0,72$ e 1,00 MPa para as umidades de $11,8,13,8$ e $15,8 \%$, respectivamente, pode-se obter proporções ótimas para fabricação de blocos de solo-cimentomaterial cerâmico. Através da utilização deste procedimento sugerem-se duas proporções ótimas: $15,8 \%$ de umidade, $6 \%$ de material ligante e $38 \%$ de substituição do cimento por material cerâmico; e 15,8\% de umidade, $8 \%$ de material ligante e $57 \%$ de substituição do cimento por material cerâmico.
A.

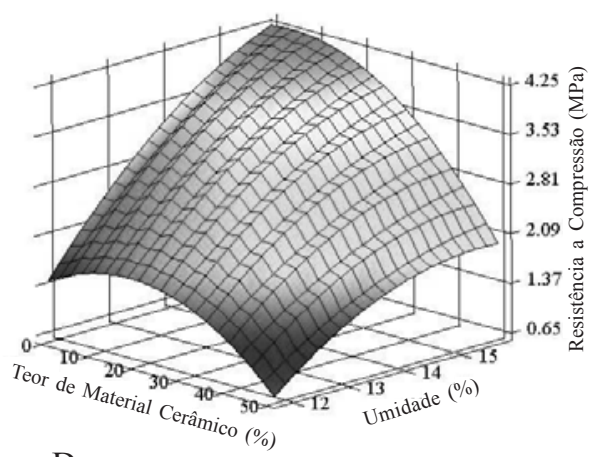

D.

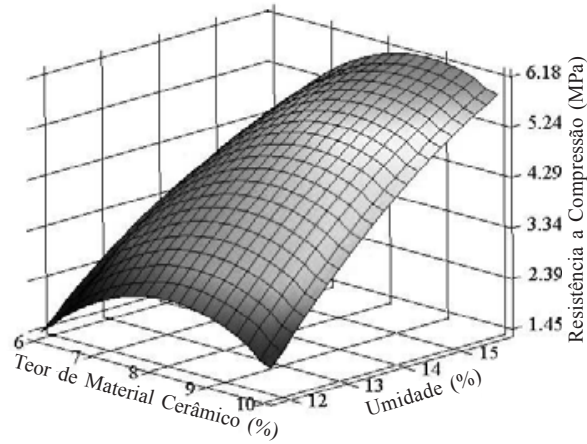

B.

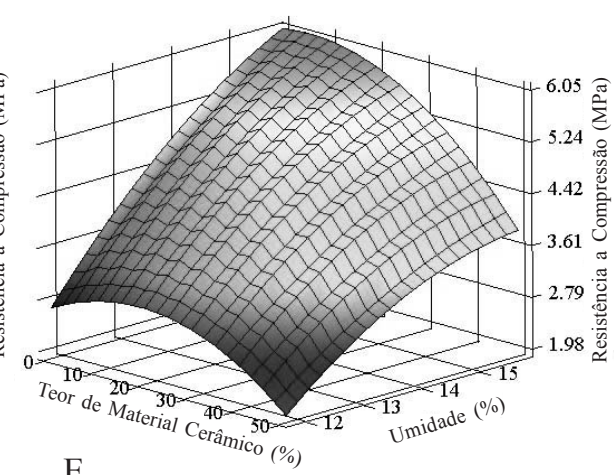

E.

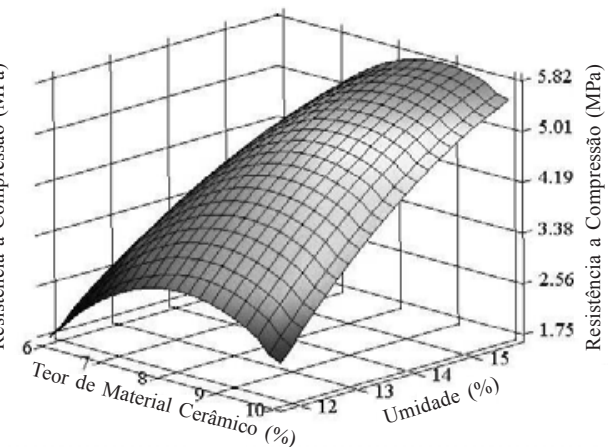

C.

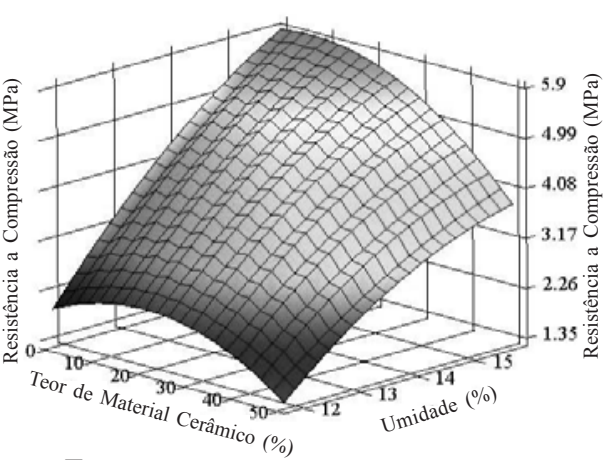

F.

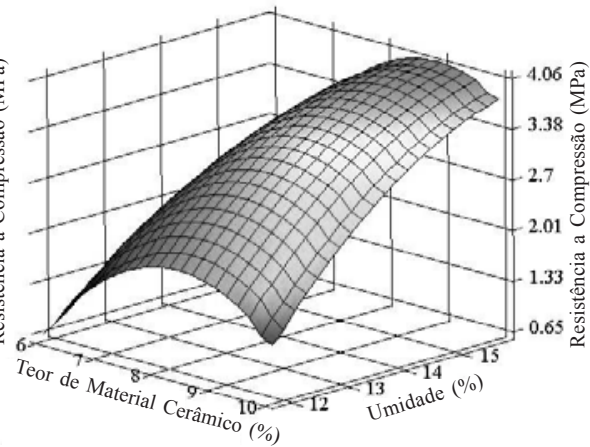

Figura 6. Representação gráfica da Eq. (2) para os teores de material ligante 6\% (A), 8\% (B) e 10\% (C) e para os teores de material cerâmico $0 \%(\mathrm{D}), 25 \%$ (E) e $50 \%$ (F) 


\section{CONCLUSÕES}

1. Os resíduos de material cerâmico moído apresentaram ação pozolânica e efeito fíler. Obtiveram-se resistências superiores a $2 \mathrm{MPa}$, com substituições de até $57 \%$, para um teor de material ligante de $8 \%$.

2. As curvas de superfície obtidas através das variações da massa específica e da resistência do solo estabilizado, podem ser utilizadas para estimativa de proporções ótimas com relação às variáveis estudadas, foram obtidas e podem ser utilizadas para obtenção de proporções ótimas para a fabricação de blocos de solo-cimento, com o solo em questão.

\section{LITERATURA CITADA}

ABCP - Associação Brasileira de Cimento Portland. Construção de paredes monolíticas com solo-cimento compactado. São Paulo, 1989, 12p. Boletim Técnico 110

ABNT - Associação Brasileira de Normas Técnicas. NBR 6459 - Ensaios de limite de liquidez. Rio de Janeiro, 1984a, 6p.

ABNT - Associação Brasileira de Normas Técnicas. NBR 6465 - Agregados - Determinação da abrasão "Los Angeles". Rio de Janeiro, 1984b, 5p.

ABNT - Associação Brasileira de Normas Técnicas. NBR 7180 - Ensaios de limite de plasticidade. Rio de Janeiro, 1984c, 3p. ABNT - Associação Brasileira de Normas Técnicas. NBR 7181 - Ensaios de granulometria por peneiramento e sedimentação. Rio de Janeiro, 1984d, 13p.

ABNT - Associação Brasileira de Normas Técnicas. NBR 5752 - Materiais pozolânicos - Determinação de atividade pozolânica com cimento Portland - Índice de atividade pozolânica com cimento. Rio de Janeiro, 1992, 3p.

Akasaki, J.L.; Silva, A.P. Estudo de composições do solo estabilizado com cal e resíduos agroindustriais. In: Congresso Brasileiro de Engenharia Agrícola, 30. 2001, Foz do Iguaçu. Anais... Foz do Iguaçu: SBEA, 2001. CD-Rom
ASTM - American Society of Testing and Materials. Fly ash and raw or calcined natural pozzolan for use as mineral admixture in Portland cement concrete. ASTM 618C. In: Annual Book of ASTM Standards, Philadelphia, USA, 1992, $3 p$.

Ay, N.; Ünal, M. The use of waste ceramic tile in cement production. Cement and Concrete Research, v.30, p.497-499, 2000.

Barbosa, N.P.; Toledo Filho, R.D.; Ghavami, K. Construção com terra crua. In: Toledo Filho, R.D.; Nascimento, J.W.B.; Ghavami, K. (eds.). Materiais não convencionais para construções rurais. Campina Grande: UFPB/SBEA, 1997. cap.4, p.113-144.

Farias Filho, F.; Toledo Filho, R.D.; Rabelo, M.S. Incremento da durabilidade de compósitos reforçados com fibras vegetais através da substituição parcial do cimento portland por metacaolinita. In: Congresso Brasileiro de Engenharia Agrícola, 30. 2001, Foz do Iguaçu. Anais... Foz do Iguaçu: SBEA, 2001. CD-Rom

Freire, W.J. Tratamento prévio do solo com aditivos químicos e seu efeito sobre a qualidade do solo-cimento. Piracicaba: Universidade de São Paulo - ESALQ, 1976, 142p. Tese Doutorado

Montgomery, D.C. Design and analysis of experiments. New York: John Wiley \& Sons. 1984, 704p.

Oliver, M. ; El Gharbi, A.Z. ; Adan, W. Proposition d'une norme déssai pour les blocs de terre comprimées. Lyon: Laboratorie Geomataeriaux, ENTPE, 1995, 13p. Document provisore de travail

PCA - Portland Cement Association. Soil primer. Illinois, 1976, 52p.

Pinto, T.P. Metodologia para a gestão diferenciada de resíduos sólidos da construção urbana. São Paulo: USP - Escola Politécnica, 1999, 189p. Tese Doutorado

Rolim, M.M.; Freire, W.J. Resistência à compressão de tijolos fabricados com solo-vinhaça concentrada. Engenharia Agrícola, Jaboticabal, v.17, n.3, p.1-8, 1998. 